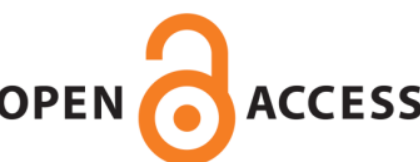

UWS Academic Portal

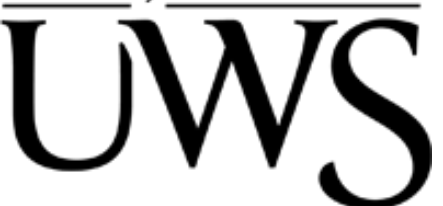

\title{
An evaluation of nurse-led mental health training for benefits staff
}

Gillespie, Mark

Published in:

Mental Health Practice

DOI:

10.7748/mhp.2019.e1395

E-pub ahead of print: 14/10/2019

Document Version

Peer reviewed version

Link to publication on the UWS Academic Portal

Citation for published version (APA):

Gillespie, M. (2019). An evaluation of nurse-led mental health training for benefits staff. Mental Health Practice. https://doi.org/10.7748/mhp.2019.e1395

\section{General rights}

Copyright and moral rights for the publications made accessible in the UWS Academic Portal are retained by the authors and/or other copyright owners and it is a condition of accessing publications that users recognise and abide by the legal requirements associated with these rights.

Take down policy

If you believe that this document breaches copyright please contact pure@uws.ac.uk providing details, and we will remove access to the work immediately and investigate your claim. 
Benefiting the public? An evaluation of nurse led mental health training for benefits staff.

\begin{abstract}
Introduction-The influence of employment and occupation in promoting and maintaining emotional and mental health is well recognised. Despite this, there are concerns around the supports offered to assist those experiencing mental ill health in maintaining or returning to employment. UWS recently collaborated with benefits staff to support their engagement with such individuals.
\end{abstract}

Background- The Department of Work and Pensions commissioned the delivery of a training programme for staff involved in job coaching. Mental health staff from one university delivered 18 of these sessions.

The training- National training materials were commissioned. The content included the concept of recovery, engagement, questioning skills, belief building, work solutions and consideration of mental health within this process.

Evaluation- Likert type and open responses were sought in relation to the participants understanding of their learning during the sessions and of the topics relevance to their work with claimants.

Conclusions- participants clearly identified the importance of training that they felt articulated with the development of their daily work practices. Additional programme content developed by these trainers also featured frequently within participant comments on the most effective components within the programme. The clinical and educational expertise of trainers was key in the successful delivery of these sessions.

Keywords

Mental health, education, benefits, employment, stigma, mental health nurses

\title{
Introduction
}


Meaningful employment fulfils a human need for purpose that influences mental health and resilience and is associated with the maintenance of mental wellbeing and recovery from mental illness. Agencies like The Scottish Recovery Network have long recognised the importance of employment in mental health care, suggesting that it is linked to self-esteem, self-identity, motivation and access to supportive social networks (Coutts, 2007). This recognition is reflected in national policy guidance and is addressed within the current mental health strategies for Scotland (Scottish Government, 2017) and England (NHS England, 2016). Both of these documents identify clear ambitions to better support those in employment who have mental health problems, and to help the unemployed who have experienced mental ill health back in to employment.

Despite these defined aims, one in six UK workers have clinically diagnosable mental health conditions, 2.3 million of the population who have mental health conditions are unemployed and mental ill health is considered the most common cause of claims for health related benefits (NMHDU, n.d.). For people experiencing mental ill health Department of Work and Pension (DWP) initiatives to support employability readiness appear to be less effective than they are for unaffected peers. Fewer than $10 \%$ of participants who have mental ill health will gain employment on completion of such return to work programmes (NHS England, 2016).

Those involved with assisting benefit claims, arranging workplace support or a return to work for individuals with mental ill health do so against a background of media concern and evidence that the process may be fraught with potentially negative consequences. This includes exacerbating the need for antidepressant prescribing and increased suicide rates for the claimants involved (Barr et al, 2015). The recent commencement of the staged roll out of the new Universal Credit benefit has intensified such concerns and the DWP has sought to address training and support needs through the introduction of several strategies, including the delivery of training for their staff involved within this process. This paper provides an evaluation of the delivery of this training, provided mainly by mental health nurses, within one benefits district in the West of Scotland.

\section{The training}


The DWP commissioned the development of a national framework of training to be offered to their staff working closest with the employment needs of people experiencing mental health problems. In the main this involved Job Coaches, though some others, such as disability employment advisors would also be expected to access the programme. The materials were developed to be delivered by two facilitators, to groups of around 12 participants over 2 consecutive days. While the training programme had been commissioned for national delivery, the materials developed were designed to accommodate local variation in service configuration. This meant involving local organisations who could deliver the materials while relating them to the resources available within the immediate environment. Any organisation with experience in mental health education could tender for the sessions and in our case the mental health department in the university was awarded several of the contracts available. The materials themselves were underpinned by social constructivist learning theory. Social constructivist learning theory emphasises the value of shared learning and learning initiatives that are reflective of the situations the desired skills and knowledge will be used in (Schreiber and Valle, 2013). In this case the sessions included small group discussion, role play and brief tutorials, with all materials strongly related to the participants work with claimants who have mental health issues. Topics covered included; the continuum of mental health, first impressions, engagement, communication skills, problem solving, collaborative working, the recovery paradigm, the role of employment, employers needs and self-care needs for DWP staff. The training incorporated elements of the solution focused approach to mental health care as well as cognitive behavioural theories, and both linked strongly to other training programmes this staff group had been exposed to.

Having been successful in tendering for training several groups of DWP staff, the University (name removed for confidentiality) allocated 6 staff to cover the sessions in one DWP district, all mental health lecturers. Five of the lecturers were mental health nurses, most formerly community mental health nurses, and the sixth a psychologist. The training was delivered over a period of 2 months in 2018 and one lecturer was present at all of the sessions, being assisted by one other for each group of participants. While the core materials were required to be delivered there was some scope for adaptation where the 
group dynamic suggested this, and any such additions were discussed and formalised during regular catch up meetings between representatives from both organisations.

\section{Evaluation}

Evaluation is suggested to differ from research in that while research seeks to deliver findings of relevance beyond an individual setting, evaluation is focused on enhancing the achievement of the goals for that one project (Fain, 2005). This evaluation used a combination of Likert type responses and open narrative to gauge participant reactions at the end of the training. This equates to completion of level one evaluation using the Kirkpatrick framework as cited by Gray (2018) and allows investigation of the level of participant satisfaction. There was no ethical approval sought for this process though protective measures were in-built in order to protect participant anonymity and confidentiality, and to encourage more honest responses. By providing free time for completion and having no individual identifiers on the evaluation form it was hoped to avoid interviewer influence and other forms of bias considered likely to emerge within similar endeavours (Moule, 2018). Participants were advised that their responses would be used to further develop the mental health training delivered to DWP staff.

The Likert type scores were calculated using the Excel 2016 Analysis Toolpak and the open narratives were clustered into themes using Richards (2015) guidance. This involved reading and re-reading the participant responses in order to develop the initial descriptive coding. The initial codes were then considered and reviewed in relation to the context of the training and this led to the development of topic codes. These codes were then considered in relation to programme goals and pedagogical underpinning, and final themes identified. Richards suggests that research projects would incorporate analytical coding as well and use this to validate emerging theory. Both sets of findings are presented below.

\section{Findings}

Five of the sessions took place within the one DWP building with the other held in another DWP district. All of the sessions included DWP staff from a mixture of nearby base offices, though all were involved in similar job roles. 61 participants took part in the sessions with the smallest group involving 8 participants, the largest 12 and the average 10 . No data were recorded around participant sex, age or prior educational accomplishment. Five questions 
were set using the Likert type format that included four possible responses. This meant responses could be recorded from disagree, through partly agree and agree as far as strongly agree. The questions set are identified in box 1 .

1. My trainers were prepared and familiar with the materials

2. My trainers encouraged participation and respected all responses

3. My knowledge of the subject has increased as a result of taking this training

4. My confidence around mental ill-health has increased

5. The training location was conducive to learning

Question 1- trainer understanding

Insert graph 1 here

It was apparent that participants were satisfied that trainers were familiar with the learning materials and had a sufficient level of background knowledge beyond the depth of the materials presented. All participants agreed to some extent that this was the case and this is important as learning seems to be enhanced when those in the teaching role appear knowledgeable and motivated (Jack, Hamshire and Chambers, 2017).

Question 2- trainers encouraging participation and respect

Insert graph 2 here

There was universal agreement that participation was encouraged and that participants felt safe in contributing to the discussion. In nurse education the presence of a supportive pedagogical environment is considered crucial in generating participant satisfaction and enhancing learning (Papastravou et al, 2016) and it seems likely that it would have been similarly relevant here.

Question 3 knowledge increase

Insert graph 3 here

While this is the first response not to show full agreement, $97 \%$ of participants reported experiencing some level of knowledge enhancement. As with the responses to the questions following this one, the less positive answers can, in the main, be attributed to one 
group. As the materials delivered to this group were the same as all other participants received, it seems likely this anomaly would be due either to issues related to the presenters or the participants, or a mixture of both. As suggested earlier, one former CMHN co-facilitated all of the sessions, and for that one group was assisted by an individual who was not a nurse.

It could be argued that the different working practices associated with that individuals profession may have led to their clinical experience being less in-tune with the participants expectations, though the presence of the nurse co-facilitator would likely have offset any such effect. The group themselves, then, may have been the reason for the different responses. It is possible that this one group contained a disproportionate number of very experienced and very knowledgeable staff. Members of the other groups, however, also appeared very experienced and several of them also identified that many of the skills and much of the theory covered within the sessions were not entirely new to them. The difference was that many of these participants were positive about this in that it confirmed the appropriateness of techniques they were already employing. Group dynamics do seem important in shaping the sense of learning for participants taught in group settings, with Baccaria et al (2014) indicating that students can feel their learning is inhibited if they are uncomfortable with the group they are part of.

Question 4 confidence

Add graph 4 here

The responses to this question were less positive than those given for the previous one. This could reflect the relatively short duration of the training and the lack of follow up support and evaluation from the perspective of the trainers. The importance of experiencing occupation based learning within the actual occupational setting is well established and is described as situated learning (Lave and Wenger, 1991). This theory suggests that learning is related to the environment within which it takes place, and has more salience for learners when the subject matter marries with the demands of the setting. The importance of this for participants more clearly emerged within the narrative discussion explored below.

Question 5 conducive location 
Add graph 5 here

The choice of location for each of the training sessions was decided by the DWP and cost effectively settled on using training rooms sited within area benefits centres. These settings, and indeed the training rooms themselves, would be familiar to all participants.

\section{Narrative feedback}

Four main themes emerged from the open narrative section of the evaluation questionnaire; Information on disorders, symptoms and treatments, the impact of their own involvement, benefits of the training format and enhanced awareness and confidence. These are discussed in detail below.

\section{Information on disorders, symptoms and treatments}

The most frequently occurring message from participants was the benefit they felt from having common mental health disorders and their symptoms and treatments explained to them. Surprisingly this material was not fully defined within the DWP training materials, with instruction only that such topics should be discussed where appropriate. The American Psychiatric Association (2018) advocate that understanding mental health symptoms and conditions is helpful as it can lead to earlier and more effective intervention, enable more positive outcomes and help manage crisis. The charity, Rethink Mental Illness (n.d.) add that development of condition related knowledge helps those working with mental ill health better understand the situation, and their responsibilities and those of others involved. Such understanding seems to remove some of the uncertainty around the role played by DWP staff and several commented favourably on the condition related information introduced by the trainers. When asked what was felt to be the most useful aspect of the training many participants focused on the benefits of increasing their knowledge in this area, and examples of this are detailed below.

Most useful aspects of the training;

"Discussing the different types of mental health and how conditions can effect claimants on a day to day basis" 
"Talking about different mental health conditions and what they mean"

\section{The impact of their own involvement}

Participants were noticeably wary of how their interactions with claimants might impact on any underlying mental health issues, an issue previously identified occurring with trainee health professionals. In a study of medical students, Lezzoni, Ramanan and Lee (2006) found that fear of worsening a person with mental ill health's condition through uninformed interaction inhibited the likelihood that the students would make any such approach. As DWP staff are normally exposed to far less health and health disorder information than medical students it could be assumed that this reluctance would be amplified. It is also apparent that the DWP's management of health related claimants is subject to considerable media and public scrutiny, further adding to the participants concerns. The uncertainty around an approach to a claimant with mental health problems was mentioned by several participants with examples given below.

Most useful aspects of the training;

"Sections on effects of mental health of the person, their actions, their perceptions and how what we might say or ask them might be perceived"

"Speaking about different mental health conditions and how to talk about them with a claimant and not be fazed"

\section{Benefits of the training format}

While the training was structured to follow a set training pack slide presentation, much of the emphasis was on small group discussion, within which the participants were encouraged to share their experiences, uncertainties, opinions and knowledge. This space for peer discussion was noted by several participants as a significant advantage of this training format.

Most useful aspects of the training; 
"(The) case conferencing with colleagues and trainers about concerns" (case conferencing for DWP staff is a supportive discussion around their interactions with a claimant, most frequently done with a more senior and more experienced colleague)

"The knowledge and facilitation and the interaction of the group"

\section{Enhanced awareness and confidence}

Having two days to specifically look at mental health and benefit claims was important as it clearly encouraged participants and trainers to focus their attention on this subject. This forced emphasis allows for a shift from the pre-conscious awareness we have around a topic, to a deeper consideration and appraisal (Smith, Flowers and Larkin, 2009). For many participants the raised awareness of mental ill health as a topic of interest generated consideration of the mental health of their colleagues and themselves, as well as that of their claimants, and reflection on their interactions around mental illness helped develop confidence around how they had managed such exchanges. Most of the participants demonstrated notably high levels of compassion and concern within the sessions, and this value base had underpinned a supportive approach to managing their previous interactions with claimants they understood as having mental health conditions. It was therefore reassuring to them that the strategies they had been employing to manage their work with such claimants was being confirmed as appropriate. Examples of this are given below;

"First day strengthened and increased what I knew and gave me more confidence" "Has increased my confidence in dealing with customers and know where to direct them"

\section{Discussion}

While participant feedback was in the main positive, there was room for improvement, particularly in the areas of knowledge and confidence development. Feedback from participants identified the importance to them of learning around topics that were clearly aligned with their daily work requirements, and through which they could develop confidence in their work practices. Standal and Jespersen (2008) found that situated learning involving peers led to participants developing a more confident understanding of their practical situation as well as enabling the testing of the applicability of the information 
being delivered by trainers. They argue that the consideration of what the participants understand as their learning needs, alongside the pre-planned teaching curriculum, is key in delivering these positive outcomes for a programme. Meeting participant expectations then may provide explanation around the effective aspects of the training and how the programme could be enhanced.

Mental health staff involvement in delivering the sessions seemed crucial to the success of the training programme, with particular benefit gained from their subject knowledge, clinical experience and familiarity with local services. This seems to have helped participants situate new knowledge around mental ill health within the context of their professional understanding. Topics added to the core programme materials that helped this included information on symptoms of common mental health conditions, the effects of psychotropic medicines and the framing of mental ill health using the Stress Vulnerability Model (Zubin and Spring, 1977). This discussion seemed to aid participants better contextualise their work needs with this claimant group, with peer discussion supporting the development of a shared understanding that previous work practices had been appropriate. At present there is growing public awareness of the need to address the emotional distress and mental ill health that presents in environments such as emergency departments, GP reception areas and through police contact. It is, therefore, important to recognise the effectiveness of the involvement of mental health nurses in training other professionals in mental health care.

The original training materials had been developed for use with the UK wide DWP workforce, and as a consequence emphasised the English health policy and NHS service structure that would have been relevant to most of that group. This does not fit well with the situated learning theory introduced above, which emphasises the need for learning initiatives to fit with the reality of the participant's occupational context. The trainers therefore replaced reference to the English experience with materials explaining the Scottish context, as well as providing detailed information on mental health support services available in the area the training was delivered. Ensuring that the participants identify the relevance of educational materials presented to them is important. Kube and colleagues (2013) recommend taking this a stage further by encouraging participants to shape their own learning programme having found that participant satisfaction with programme 
content increased markedly when this takes place. Elements of participant driven content should therefore be considered for future iterations of this training programme.

The opportunity for group discussion around situations the participants found troublesome encouraged the sharing of experience. Participant feedback suggested that this helped develop confidence around managing difficult situations, and this was at least partially due to group confirmation of appropriate ways of working. This process fits with elements of Johns (2013) typology of reflective practices, wherein it incorporates both the foundational level reflection occurring after the event, as well as the more expansive reflection that comes through discussion with others. This facilitated and shared reflection on practice fits closely with what Beddoe and Davys (2016) describe as group professional (or clinical) supervision, which they suggest when effectively delivered, is considered to generate professional and personal development through peer interaction.

Participants here confirmed that they were encouraged to seek support for managing complex cases through the process of case conferencing. This involved them discussing the situation with a line manager or more experienced colleague. While this was identified as an option for DWP staff, it was apparent that its use was not strongly associated with seeking help around developing competencies for managing clients with mental health concerns. It may be useful, therefore, to incorporate some form of professional supervision framework within the DWP staff group to support professional reflection and development. Jasper, Rosser and Mooney (2013) frame the involvement of reflection in professional development using their ERA model; Experience- Reflection- Action. Developing a supervision structure within the DWP workforce would support this while also offering a platform to assist embedding the learning arising from this training programme.

\section{Conclusions}

While this programme evaluation has generated information pertinent to the development of the ongoing mental health training delivered to DWP staff, it has also highlighted issues with relevance beyond that. Much of the feedback supported the situated learning concept around the importance of learning taking place within the context of its professional application, and through the involvement of experts and peer learners. Both of these 
should be emphasised during the drafting of training programmes for professional groups and in consideration of the processes to help embed the learning arising for the sessions within the participant's everyday practice. There is a significant role for the involvement of experienced mental health practitioners in the development and delivery of such training and in the shaping of supportive supervision frameworks, and the clinical experience, local familiarity and knowledge base of mental health nurses in particular supports their involvement in this. The effectiveness of mental health nurses delivering this training suggests suitability for their involvement in the educational development of other staff groups and organisations, and that this is a role mental health nurses should be embracing. It is also important to recognise the steps taken by the DWP to support what presented as a caring, compassionate and knowledgeable workforce in the delivery of what is often a contentious service. Such recognition may assist DWP staff by reducing media antagonism and enhance service delivery through alleviating pressures experienced by this workforce.

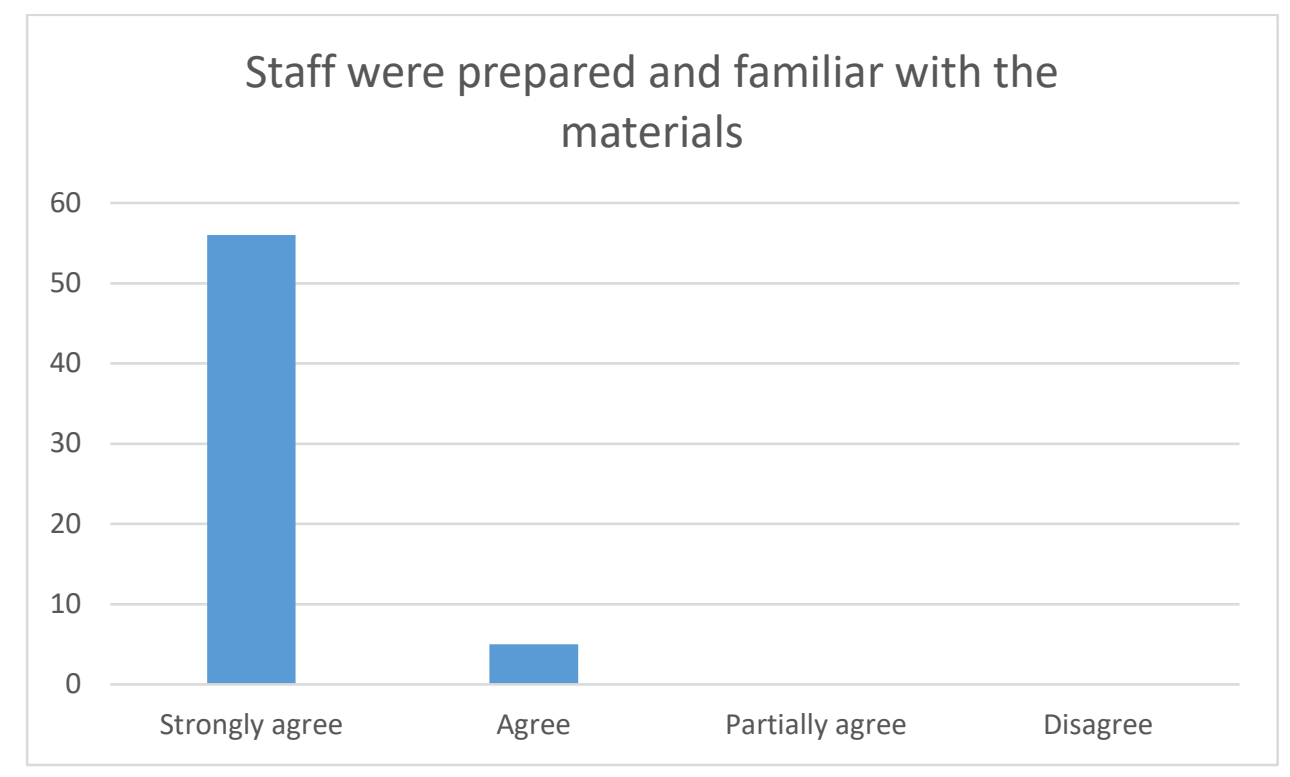

Table 1- staff were prepared and familiar with materials 


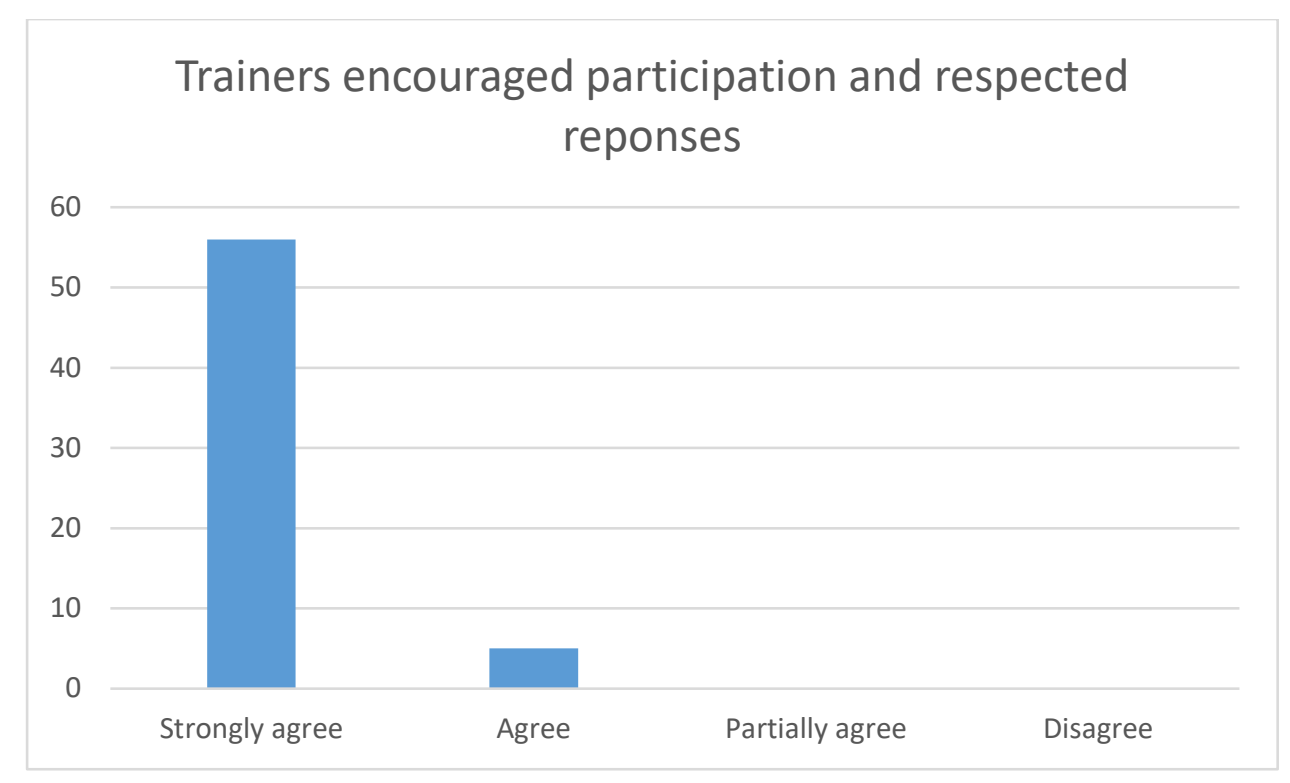

Table 2- Trainers encouraged participation

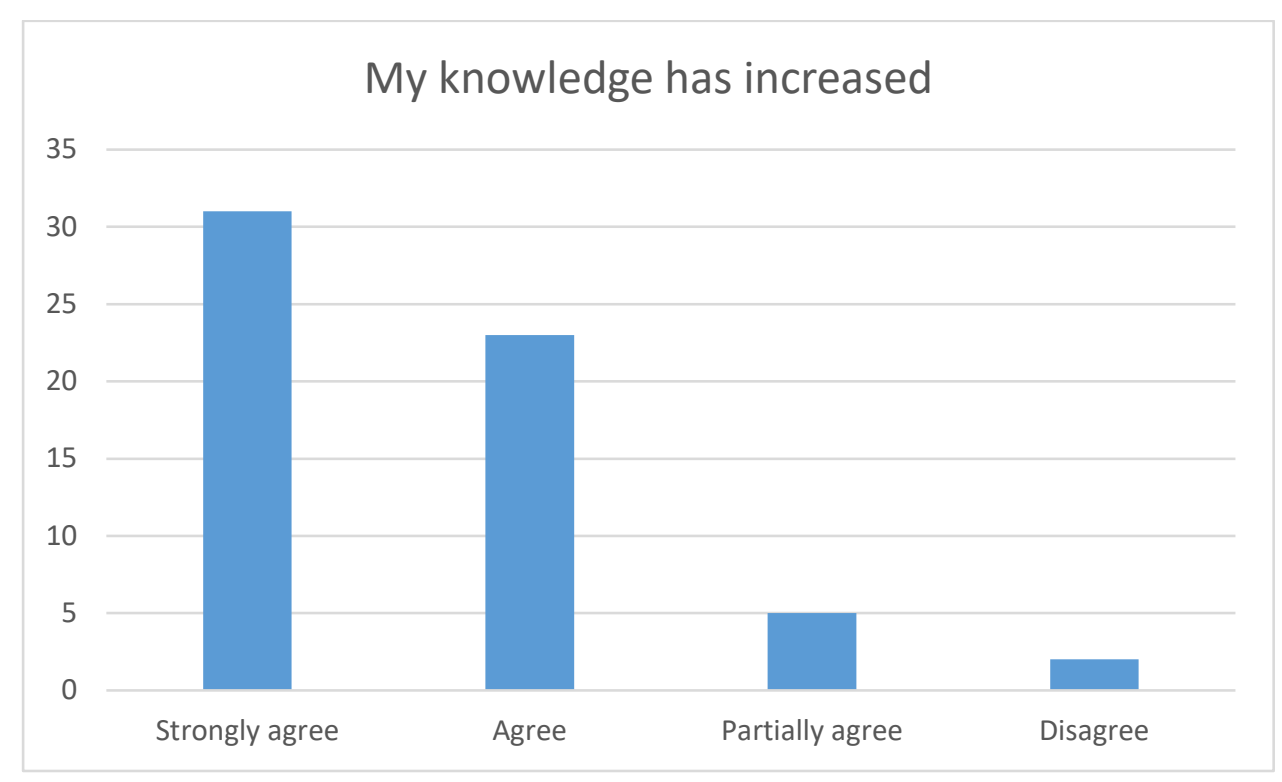

Table 3- my knowledge increased 


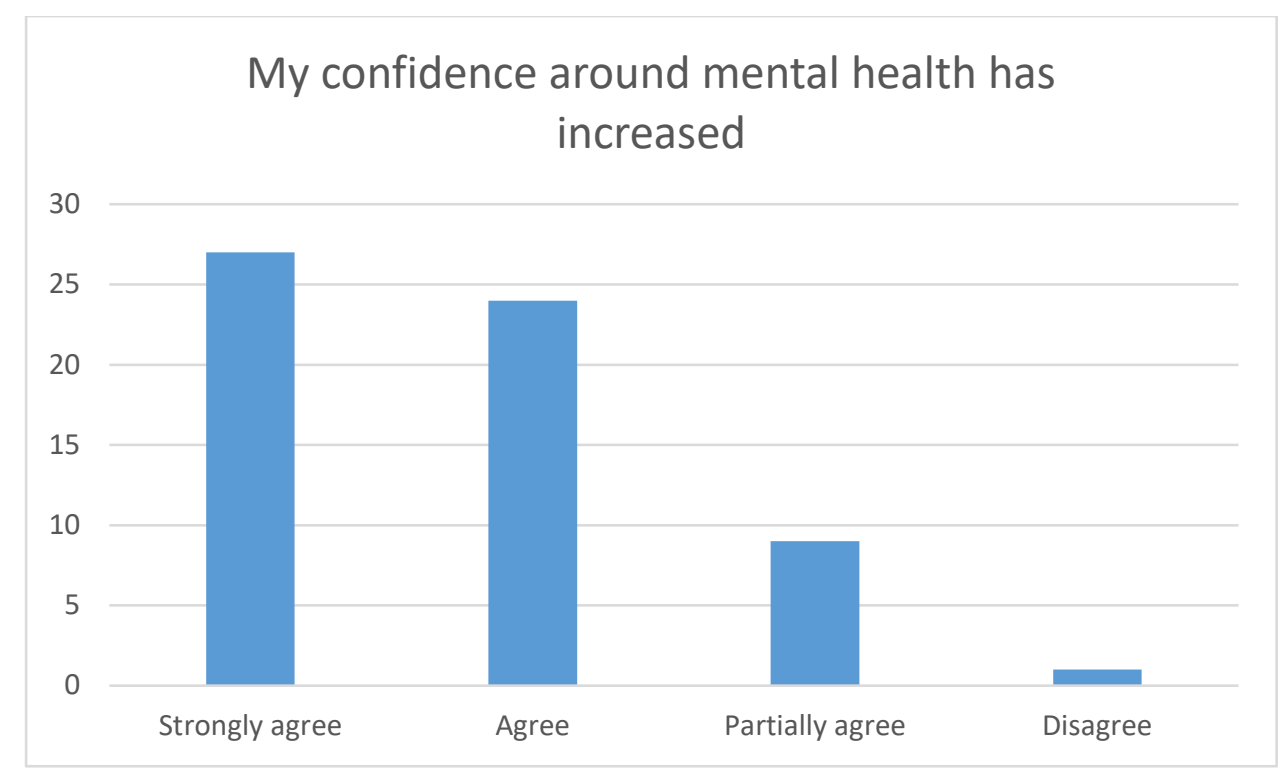

Table 4- my confidence around mental health has increased

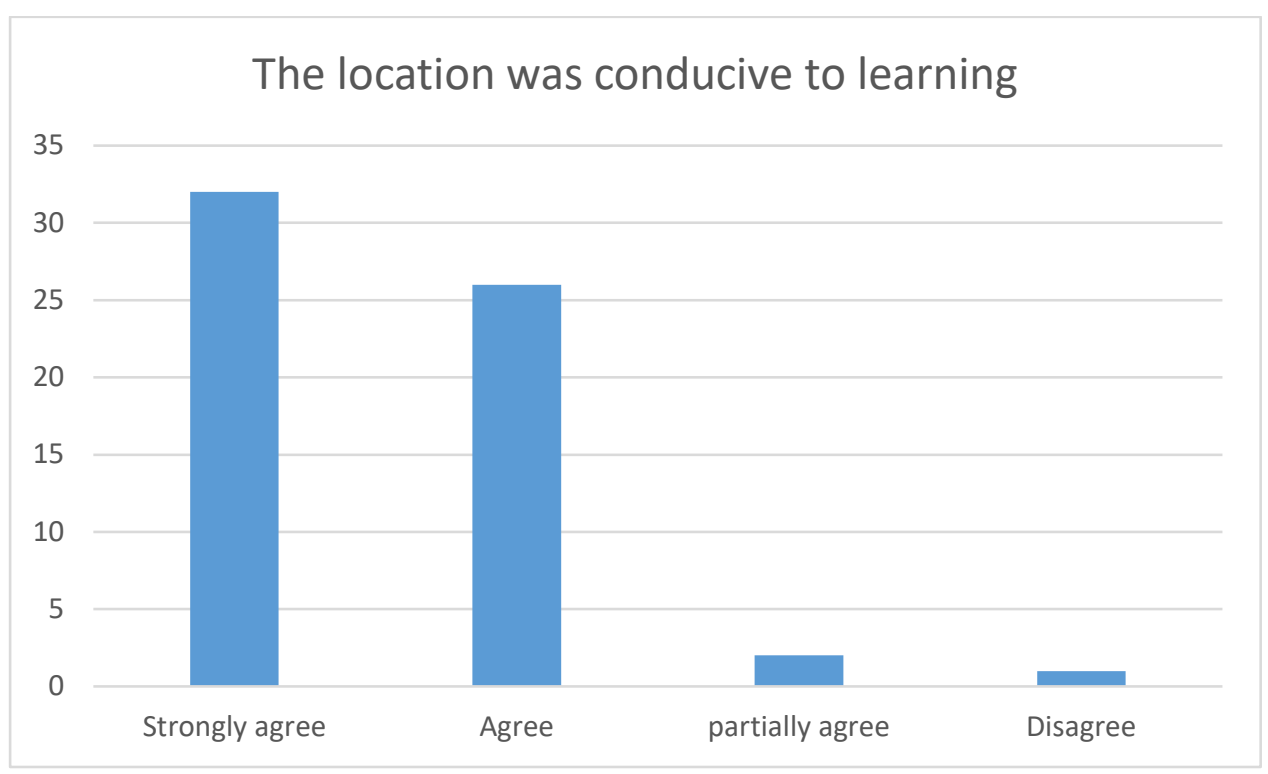

Table 5- the location was conducive to learning 
References

American Psychiatric Association (2018) Warning signs of mental illnesses. Accessed at https://www.psychiatry.org/patients-families/warning-signs-of-mental-illness

Baccaria, L. Kek, M. Huijser, H. Rose, J and Kimmins, L (2014) The interrelationship between student approaches to learning and group work. Nurse Education Today. 34. Pp. 1094-1103.

Barr, B. Taylor-Robinson, D. Stuckler, D. Loopstra, R. Reeves, A and Whitehead, M (2015) "First, do no harm": are disability assessments associated with adverse trends in mental health? A longitudinal ecological study. Journal of Epidemiology and Community Health. 70 (4).

Beddoe, L and Davys, A (2016) Challenges in professional supervision; current themes and models for practice. London. Jessica Kingsley Publishers.

Coutts, P (2007) Mental health, recovery and employment. SRN discussion paper series. Report No.5. Glasgow. Scottish Recovery Network.

Fain, J, A (2005) Is there a difference between evaluation and research? The Diabetes Educator. 31 (2). Pp. 154-155.

Jack, K. Hamshire, C and Chambers, A (2017) The influence of role models in undergraduate nurse education. Journal of Clinical Nursing. 26 (23-24) Pp. 4707-4715.

Jasper, M. Rosser, M and Mooney, G (2013) Professional development, reflection and decision making in nursing and health care (2nd edition). Chichester. Wiley Blackwell. Johns, C (2013) Becoming a reflective practitioner (4 ${ }^{\text {th }}$ Edition). Chichester. Wiley Blackwell. Kube, D. Bishop, E. A. Ruth, J, M and Palmer, F. B (2013) Evaluation of a parent led curriculum in developmental disabilities for pediatric and medicine/ pediatric residents. Maternal Child health Journal. 17. Pp. 1304-1308.

Lave, J and Wenger, E (1991) Situated learning; legitimate peripheral participation. Cambridge: Cambridge University Press. 
Lezzoni, L. I, Ramanan, R. A and Lee, S (2006) Teaching medical students about communicating with patients with major mental illness. Journal of General Internal Medicine. 21 (10). Pp. 1112-1115.

Moule, P (2018) Making sense of research in health and social care. London. Sage.

NHS England (2016) The Five Year Forward View for Mental Health. Online. Accessed at https://www.england.nhs.uk/wp-content/uploads/2016/02/Mental-Health-Taskforce-FYFVfinal.pdf

NMHDU (n.d.) Policy into practice; mental health and employment. London. NMHDU. Scottish Government (2017) Mental Health Strategy 2017- 2027. Online. Accessed at https://www.gov.scot/publications/mental-health-strategy-2017-2027/pages/5/

Papastravou, E. Dimitriadou, M. Tsangari, H and Andreou, C (2016) Nursing students' satisfaction of the clinical learning environment: a research study. BMC Nursing. https://dx.doi.org/10.1186\%2Fs12912-016-0164-4

Rethink Mental Illness (n.d.) Supporting someone with a mental illness. Accessed at https://www.rethink.org/carers-family-friends/what-you-need-to-know/supportingsomeone-with-a-mental-illness

Richards, L (2015) Handling qualitative data; a practical guide. (3rd Edition). London. Sage. Schreiber, L. M and Valle, B. E (2013) Social constructivist teaching strategies in the small group classroom. Small Group Research. 44 (4). Pp. 395-411.

Smith, J. A., Flowers, P., \& Larkin, M (2009). Interpretative Phenomenological Analysis; theory, method and research. London: Sage.

Standal, O. F and Jespersen, E (2008) peers as resources for learning: a situated learning approach to adapted physical ability in rehabilitation. Adapted Physical Ability Quarterly. 25. Pp. 208-227.

Zubin, J, and Spring, B (1977) Vulnerability: A New View on Schizophrenia. Journal of Abnormal Psychology. 86. PP. 103-126 